\title{
The development of poly-L-arginine-coated liposomes for gene delivery
}

This article was published in the following Dove Press journal:

International Journal of Nanomedicine

6 October 2011

Number of times this article has been viewed

\section{Praneet Opanasopit \\ Jintana Tragulpakseerojn' \\ Auayporn Apirakaramwong' \\ Tanasait Ngawhirunpat' \\ Theerasak Rojanarata' \\ Uracha Ruktanonchai ${ }^{2}$ \\ 'Faculty of Pharmacy, Silpakorn University, Nakhon Pathom, Thailand; ${ }^{2}$ National Nanotechnology Center, \\ Thailand Science Park, Pathumthani, Thailand}

Correspondence: Praneet Opanasopit

Department of Pharmaceutical

Technology, Faculty of Pharmacy,

Silpakorn University, Nakhonpathom,

Thailand

Tel +66 34255800

Fax +66 3425580

Email praneet@su.ac.th

\begin{abstract}
In this study, liposomes coated with cationic polymers, poly-L-arginine (PLA), were assessed as a promising gene transfer system in human cervical carcinoma (HeLa) cells and human hepatoma cell line (Huh7) cells. The liposomes were prepared using egg yolk phosphatidylcholine and sodium oleate in the molar ratio of 10:2 with an ultrasonic generator and then coated with PLA. The PLA-coated liposomes (PCLs) formed complexes with plasmid DNA encoding green fluorescent protein. The complexes were characterized by agarose gel electrophoresis and investigated for their transfection efficiency in HeLa and Huh7 cells. The data were compared with PLA/DNA complexes and the positive control Lipofectamine $2000^{\mathrm{TM}}$. The results showed that complete PCL/DNA complexes were formed at weight ratios of more than 0.05 . Efficient gene transfer by PCLs was dependent on the cell type. The transfection efficiency of PCLs was about two times higher than that of PLA/DNA complexes in both HeLa cells and Huh7 cells. Cytotoxicity was determined by the 3-(4,5-dimethylthiazol-2-yl)2,5-diphenyl tetrazolium bromide assay and showed that $80 \%-100 \%$ of both of the cells were viable after treating PCL/DNA complexes. The present results demonstrate that PCLs are a promising, nonviral gene carrier with low toxicity.
\end{abstract}

Keywords: PLA-coated liposomes, PLA, gene delivery, transfection efficiency

\section{Introduction}

Efficient and safe gene transfer systems are the fundamental basis for gene therapy, as well as for many other laboratory applications. ${ }^{1}$ Cationic polymers and liposomes are widely used for nonviral gene delivery. ${ }^{2,3}$ Cationic liposomes form a complex with anionic DNA molecules and are hypothesized to deliver DNA through the endosomal pathway. The cationic liposomal system, however, has the disadvantages of low efficiency of transfection due to DNA degradation in lysosomes and high cytotoxicity. Therefore, there has been an intense effort to develop cationic lipid/DNA complexes (lipoplexes) that efficiently transfer genes. These efforts have included the synthesis of new cationic lipids, ${ }^{4}$ the development of new formulations of existing cationic lipids, ${ }^{5,6}$ and the addition of third components, such as a polycation or cationic peptide. ${ }^{7-12}$

Cationic polypeptides have been extensively used as tools for gene carriers. The main reason for using cationic polypeptides is that cationic polymer vectors provide flexible DNA-carrying capacity and are simple to use. The nature of the basic peptide in efficient protein transduction and in nucleic acid binding prompted us to explore the possibility of DNA transfection by these peptides. ${ }^{13}$ From the study of polypeptide/DNA complexes, the physicochemical properties and the transfection efficiency of the complexes correlated to the type and molecular weight (MW) of 
the polypeptide. In addition, it has been reported that the biological activities of the transfection reagents are highly associated with their physicochemical properties. ${ }^{14,15}$ For example, various types and MW of polypeptides, weight ratios, and $\mathrm{pH}$ of transfection medium were demonstrated to influence the physicochemical properties and transfection efficiency of polypeptide/DNA complexes. ${ }^{16-19}$

Recently, some peptide sequences, known as protein transduction domains or membrane translocalization signals, were identified and introduced for the delivery of plasmid DNA. ${ }^{20,21}$ Interestingly, it is known that these sequences usually contain positively charged amino acid residues, such as arginine and lysine, which have been reported to be able to enhance transportation into cells. ${ }^{13,22}$ Additionally, oligoarginine conjugates demonstrated characteristics similar to cell-penetrating peptides in cell translocation, and the transfection efficiency in human cervical carcinoma (HeLa) cells was highly improved by conjugating oligo-arginine to PEG-ylated lipids. ${ }^{23}$ A polyamidoamine dendrimer conjugated with L-arginine also showed enhanced gene delivery compared with the native dendrimer. ${ }^{24}$

Previously, we investigated the effect of cationic polypeptides (poly-L-lysine, poly-L-arginine [PLA], and poly-L-ornithine) mixed with chitosan (CS) on in vitro transfection efficiency and cytotoxicity in HeLa cells. ${ }^{25}$ The high transfection efficiency was dependent on the type and MW of the polypeptides, the weight ratio, and the order of mixing. Among the carriers, PLA showed the highest transfection efficiency. The highest transfection efficiency, observed in ternary complexes of PLA/DNA/CS at the weight ratio of $2: 1: 4$, was significantly higher than that of PLA/DNA complexes (2.4 times) and CS/DNA complexes (47 times). Therefore, in this study, we intended to develop an effective nonviral gene transfer system by combining the advantages of both liposomes and polycations. The polycation liposomes were prepared by coating liposomes with PLA and then complexing with DNA. Their physicochemical properties, such as complex formation, particle size, and zeta potential, were also investigated. A number of variables influencing transfection efficiency and cytotoxicity, including carrier/DNA weight ratio, cell types (HeLa and Huh7 cells), and serum in transfection medium, were investigated.

\section{Materials and methods Materials}

PLA with an average $\mathrm{MW}$ of $>70 \mathrm{kDa}$, sodium oleate $(\mathrm{NaO})$, and 3-(4,5-dimethylthiazol-2-yl)-2,5-diphenyl tetrazolium bromide (MTT) were purchased from Sigma-Aldrich (St Louis, MO). Polyethylenimine (PEI; MW 25 kDa) was purchased from Aldrich (Milwaukee, WI). Egg yolk phosphatidyl choline (EPC) was purchased from Wako Pure Chemical (Osaka, Japan). Minimum Essential Medium Eagle (MEM), Roswell Park Memorial Institute (RPMI), Trypsin-EDTA, penicillin and streptomycin antibiotics, fetal bovine serum (FBS), and Lipofectamine $2000^{\mathrm{TM}}$ were obtained from GIBCO-Invitrogen (Grand Island, NY). The pEGFP-C2 plasmid DNA encoding green fluorescent protein (GFP) was obtained from Clontech (Palo Alto, CA). The $\lambda$ DNA/HindIII marker was obtained from Promega (Madison, WI). Huh7 cells and HeLa cells were obtained from American Type Culture Collection (Rockville, MD). All other chemicals were of cell culture and molecular biology quality.

\section{Plasmid preparation}

pEGFP-C2 was propagated in Escherichia coli DH5- $\alpha$ and purified using the Qiagen endotoxin-free plasmid purification kit (Qiagen, Santa Clarita, CA). DNA concentration was quantified by the measurement of UV absorbance at $260 \mathrm{~nm}$ using a GeneRay UV Photometer (Biometra ${ }^{\circledR}$ ). The purity of the plasmid was verified by gel electrophoresis $(0.8 \%$ agarose gel) in Tris acetate-EDTA (TAE) buffer $\mathrm{pH} 8.0$ using $\lambda$ DNA/ HindIII as the DNA marker.

\section{Preparation of PLA-coated liposomes}

Anionic liposomes composed of EPC: $\mathrm{NaO}$ (10:2 molar ratio) were prepared by sonication. Briefly, EPC and $\mathrm{NaO}$ were separately dissolved in chloroform:methanol $(2: 1 \mathrm{v} / \mathrm{v})$. The materials were deposited in a test tube, and the solvents were evaporated under nitrogen gas flow. The lipid film was placed in a desiccator connected to a vacuum pump for 6 hours to remove remaining organic solvents. The dried lipid film was hydrated with Tris buffer (20 mM Tris and $150 \mathrm{mM} \mathrm{NaCl}$, pH 7.4). Following hydration, the dispersion was sonicated in a bath sonicator for 10 minutes and then in a probe sonicator for two cycles of 30 minutes each. For PLA-coated liposomes (PCLs), the liposomes were mixed with PLA solution $(1 \mathrm{mg} / \mathrm{mL})$ at the ratio of $1: 1(\mathrm{w} / \mathrm{w})$ with a magnetic stirrer for 30 minutes.

\section{Preparation of complexes}

The PLA/DNA and PCL/DNA complexes were prepared at various weight ratios of $1,2,2.5,3$, and 4 by adding $1 \mu \mathrm{g}$ of DNA (pEGFP-C2) solution to the PLA or PCL solution. The mixture was gently mixed using a pipette for 3-5 seconds to 
initiate complex formation and left for 15 minutes at room temperature.

\section{Characterization of complexes}

The complex formation was confirmed by electrophoresis (MyRun Intelligent, Cosmo Bio, Japan). Agarose gels were prepared with $0.7 \%$ agarose in TAE buffer with ethidium bromide $(0.5 \mu \mathrm{g} / \mathrm{mL})$. The electrophoresis was carried out for 60 minutes at $100 \mathrm{~V}$. The volume of the sample loaded in the well was $15 \mu \mathrm{L}$ of the complex containing $1 \mu \mathrm{g}$ of DNA.

\section{Size and zeta potential measurements}

The particle size and surface charge of PLA/DNA complexes and PCL/DNA complexes were determined by photon correlation spectroscopy using a Zetasizer Nano ZS (Malvern Instruments Ltd, Malvern, UK) at room temperature. The complexes were diluted with distilled water that had been passed through a $0.22 \mu \mathrm{m}$ membrane filter prior to use. All samples were measured in triplicate.

\section{In vitro transfection studies using cell cultures}

HeLa and Huh7 cells were maintained in MEM and RPMI at $\mathrm{pH} 7.4$, supplemented with 10\% FBS, $2 \mathrm{mM}$ L-glutamine, and $1 \%$ nonessential amino acid solution in a humidified atmosphere $\left(5 \% \mathrm{CO}_{2}, 95 \%\right.$ air, $\left.37^{\circ} \mathrm{C}\right)$. The cells were grown under standard conditions until $60 \%-70 \%$ confluency. The cells were seeded into a 24 -well plate at a density of $2 \times 10^{4}$ cells/well and grown for 24 hours. PLA/DNA and PCL/ DNA complexes were suspended in a serum-free medium and incubated for 30 minutes at room temperature. Prior to transfection, the culture medium was removed, and the cells were rinsed with phosphate-buffered saline (PBS, $\mathrm{pH}$ 7.4) and then supplied with complex solutions at various weight ratios. The cells were incubated with complexes for 24 hours at $37^{\circ} \mathrm{C}$ under a $5 \% \mathrm{CO}_{2}$ atmosphere, then washed with PBS once and grown in culture medium for 24 hours. For the fluorescence assay, the cells were directly viewed under a fluorescence microscope (model: GFP-B, wavelengths: excitation filter 480/40 and emission filter 535/50). The transfection efficiency was calculated by the number of transfected cells per unit area of a 24-well tissue culture plate $\left(1.9 \mathrm{~cm}^{2}\right)$.

\section{Cytotoxicity studies}

MTT is a tetrazolium salt that is cleaved into a dark blue product by mitochondrial dehydrogenases in living but not dead cells. ${ }^{26} \mathrm{HeLa}$ and Huh7 cells were seeded at a density of $8 \times 10^{3}$ cells/well in 96-well cell culture plates and preincubated for 24 hours before PLA and PCL treatment. The cells were then treated with PLA and PCL at various concentrations $(0.001-1 \mathrm{mg} / \mathrm{mL})$ in serum-free medium, $\mathrm{pH}$ 7.4 for 24 hours. Dilutions of PLA and PCL were made using serum-free medium to ensure that the cells did not die from nutrition deficiency. The PLA/DNA and PCL/DNA complexes were supplied in the same concentrations as used in the in vitro transfection experiment. After treatment, the samples were removed, fresh cell culture medium was added, and the cells were incubated for 24 hours to stabilize. Finally, the cells were incubated with $100 \mu \mathrm{L}$ MTT-containing medium $(0.1 \mathrm{mg} / \mathrm{mL}$ MTT in serum-free medium) for 4 hours. Then, the medium was removed, and the formazan crystals formed in the living cells were dissolved in $100 \mu \mathrm{L}$ dimethyl sulfoxide. The relative viability (\%) was calculated based on absorbance at $550 \mathrm{~nm}$ using a microplate reader (Universal Microplate Analyzer, Models AOPUS01 and AI53601, Packard BioScience, CT). Viability of nontreated control cells was arbitrarily defined as $100 \%{ }^{27}$

Relative cell viability $=\frac{\left(\mathrm{OD}_{550 \text {,sample }}-\mathrm{OD}_{550, \text { blank }}\right) \times 100}{\left(\mathrm{OD}_{550, \text { control }}-\mathrm{OD}_{550, \text { blank }}\right)}$

\section{Statistical analysis}

All experimental measurements were collected in triplicate. The values are expressed as the mean \pm standard deviation (SD). Statistical significance of differences in cell viability were examined using one-way analysis of variance (ANOVA) followed by Fisher's Least Significant Difference (LSD) test. The significance level was set at $P<0.05$.

\section{Results and discussion} Characterization of PCL/DNA complexes

To determine the optimal complexation conditions, it was necessary to evaluate the degree of binding between either PCL or DNA at different weight ratios. The formation of complexes between PCL and the pEGFP-C2 plasmid DNA was visualized by agarose gel electrophoresis. To vary the weight ratio of each complex, the PLA or PCL fraction was changed while the DNA concentration was kept constant. The complex formation between the carrier and DNA was found to depend on the weight ratio (Figure 1). When the concentration of the carrier gradually increased, the DNA was increasingly retained within the gel loading well. Migration of the DNA on the agarose gel was retarded, resulting from the charge neutralization of the complexes. 


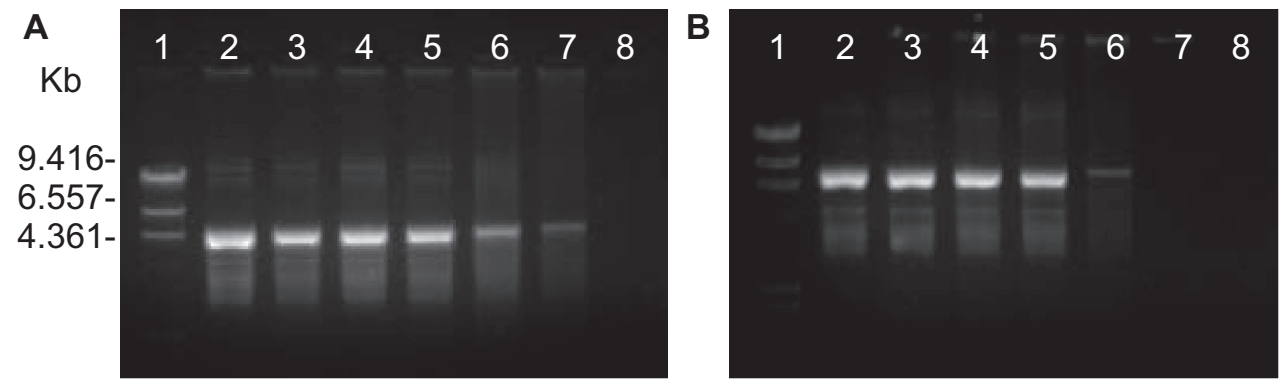

Figure I Gel retardation analysis of (A) poly-L-arginine (PLA)/DNA complexes and (B) PLA-coated liposomes (PCL)/DNA complexes: lane I, $\lambda$ Hind III DNA marker; lane 2, pEGFP-C2 plasmid; lanes 3-8, carrier/DNA complexes at weight ratios of $0.001,0.005,0.01,0.05,0.1$, and 0.5 , respectively.

The complexes had completely formed when the DNA was totally retained within the well. The complete complexation of PLA/DNA was successful at weight ratios above 0.1 , whereas PCL/DNA was formed above 0.05 . These results revealed that the PCL had a stronger binding affinity for DNA than did PLA.

The particle size and zeta potential of PLA/DNA and PCL/DNA complexes at various weight ratios were determined and plotted against the weight ratios of the PLA/DNA (Figure 2A) and PCL/DNA complexes (Figure 2B). The particle sizes of the PLA/DNA complexes at weight ratios from 1 to 3 were in the range of $200 \mathrm{~nm}$ to $700 \mathrm{~nm}$, which is slightly smaller than those seen for the PCL/DNA complexes
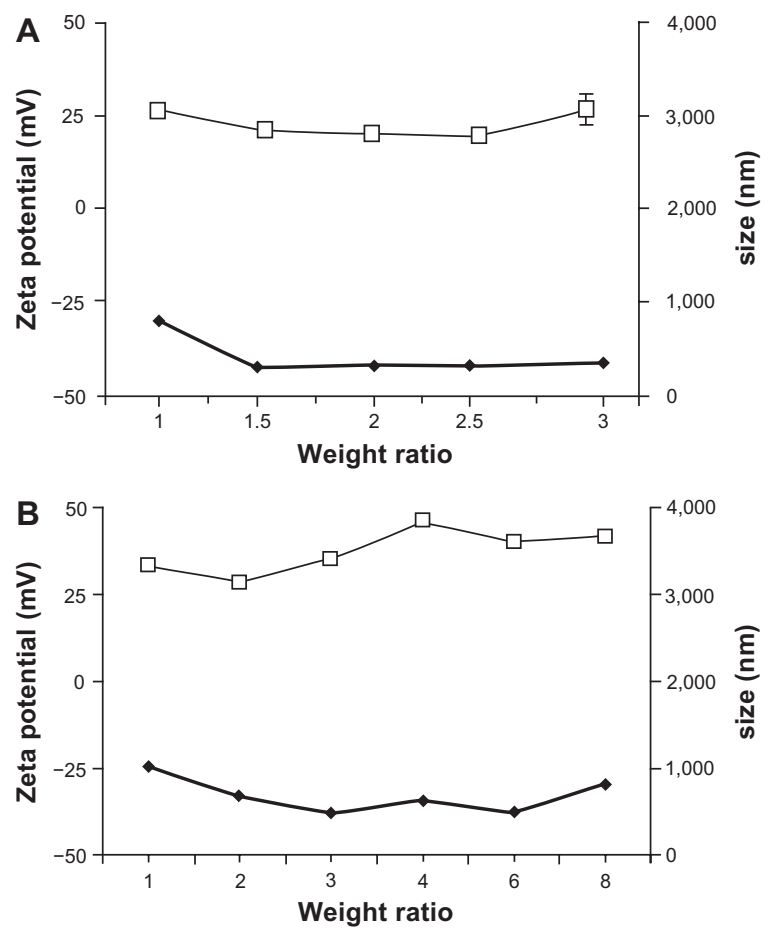

Figure 2 Zeta potential $(\square)$ and particle size $(\diamond)$ at varying weight ratios of complexes formulated with (A) poly-L-arginine (PLA)/DNA and (B) PLA-coated liposomes (PCL)/DNA.

Note: Each value represents the mean \pm SD of three measurements. at weight ratios from 1 to $8(400 \mathrm{~nm}$ to $1000 \mathrm{~nm})$. The particle size of both complexes decreased with increasing weight ratio (Figure 2). This finding was due to the intermolecular cross-linking between the DNA strands by self-aggregates, which is a phenomenon typically observed with either high DNA concentrations or excess polycations.

The zeta potential is a function of the surface charge that develops when any material is placed in a liquid and is a good index of the electrostatic properties of colloidal particles. ${ }^{28}$ An initial negative value of the zeta potential was observed for anionic liposomes $(\mathrm{PC} / \mathrm{NaO})$. On the other hand, the PCL at 1:1 (w/w) showed positive zeta potentials. The zeta potentials of the PCL/DNA complexes were found to increase with increasing weight ratio of PCL due to the higher density of protonated amines in the PCL. A similar result was observed in PLA (Figure 2A).

\section{In vitro transfection}

The achievement of high gene transfection efficiency is a final goal for the development of novel gene carriers. To investigate the PLA- and PCL-mediated gene transfection efficiencies, an in vitro gene transfection assay was performed with HeLa cells and Huh7 cells using the pEGFP-C2 plasmid encoding GFP. PCL formulations were prepared using anionic liposomes (EPC: $\mathrm{NaO}$ in the molar ratio of 10:2) and then coated with PLA at the weight ratio of $1: 1$.

To investigate the optimum conditions for gene transfection, PLA and PCL were complexed with DNA at various weight ratios of 1, 1.5, 2, 3, and 4. PEI and Lipofectamine 2000 complexed with DNA in the weight ratios of 1 and 2, respectively, were used as the positive controls. In all studies, there was no transfection in the controls (cells without complexes) or naked DNA. The results of transfection efficiency for PLA and PCL are shown in Figure 3. The transfection efficiencies increased up to a maximum when the weight ratio increased, then decreased with further 

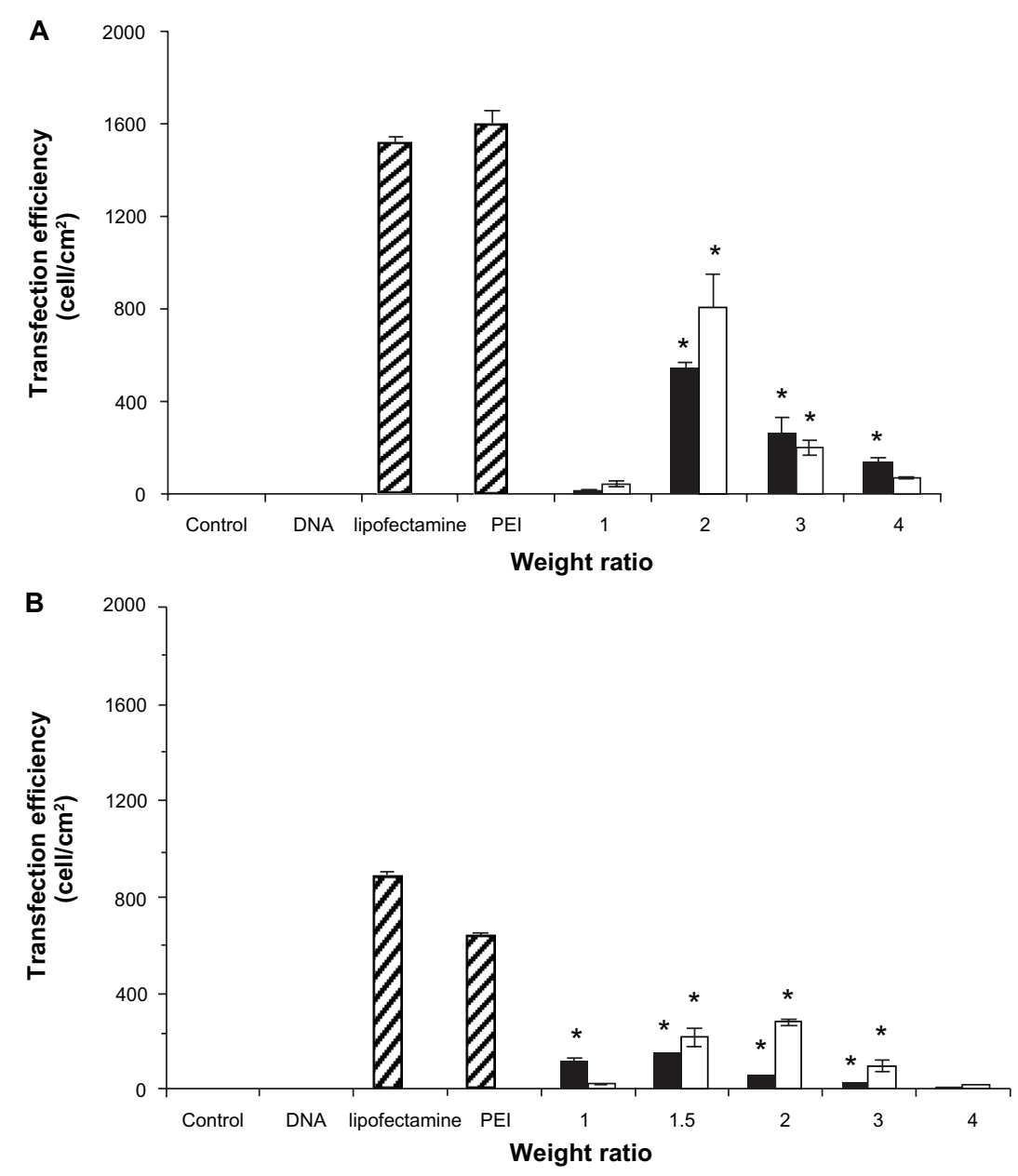

Figure 3 Transfection efficiencies of complexes formulated with (-)poly-L-arginine (PLA)/DNA and ( $\square$ ) PLA-coated liposomes (PCL)/DNA in (A) human cervical carcinoma cells and (B) human hepatoma cell line cells.

Note: Each value represents the mean \pm SD of three wells. *Difference values were statistically significant $(P<0.05)$.

incremental changes to this ratio. In both cells (HeLa and Huh7), the PCL formulations were much more effective for gene transfer than the conventional polyplexes (PLA/ DNA complexes). In the HeLa cells, the highest transfection efficiency of the PCL/DNA complexes at a weight ratio of 2 was $808.95 \pm 138.59 \mathrm{cell} / \mathrm{cm}^{2}$. For comparison, the highest transfection efficiency of the PLA/DNA complexes at a weight ratio of 4 was $543.86 \pm 22.34 \mathrm{cell} / \mathrm{cm}^{2}$. PCL showed a 1.5 times higher gene expression than the polyplex prepared with the same polymer (PLA) (Figure 3A). In the Huh7 cells, PCL showed the highest transfection efficiency at a weight ratio of $1.5\left(304.74 \pm 9.52 \mathrm{cell} / \mathrm{cm}^{2}\right)$, which is approximately two times higher than that of PLA at the weight ratio of 1.5 $\left(153.16 \pm 1.8 \mathrm{cell} / \mathrm{cm}^{2}\right)$.

Polypeptide liposomes have been hypothesized to be promising transfection agents. Liposomes modified with peptide have also shown remarkable transfection efficiency, including oligopeptide/cholesterol derivatives (DMBChol), oligopeptide/dioleoyl-phosphatidylethanolamine
(DOPE), poly-L-lysine/DC-chol/DOPE liposomes, peptide ligand-EPC lipids, NLS peptide-DOSPA (cationic lipid), and NLS peptide-DOPE (neutral lipid). ${ }^{29,30}$ Furthermore, previous studies reported that the transfection efficiency of

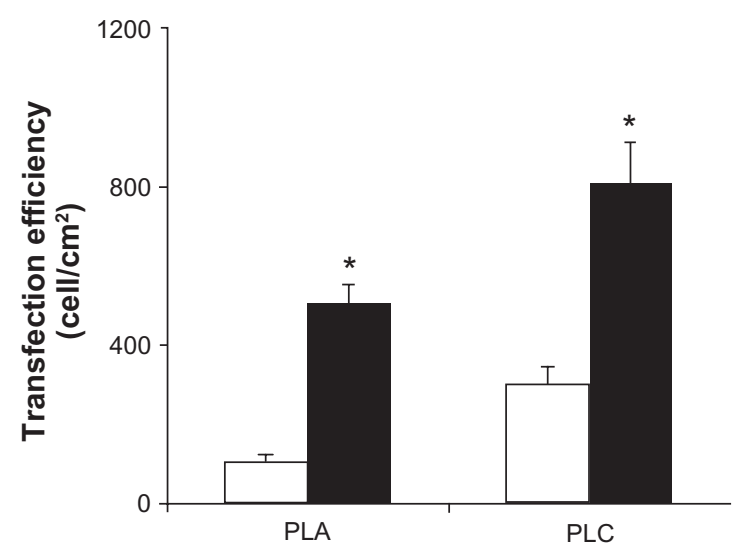

Figure 4 Comparison of the transfection efficiencies of poly-L-arginine (PLA)/DNA and PLA-coated liposomes (PCL)/DNA complexes in human cervical carcinoma cells with (口) $10 \%$ serum and ( $\square$ ) without serum in the transfection reagent. 
cationic liposomes was dependent on the serum. As shown in Figure 4, the PLA- and PCL-associated gene expressions were inhibited by the presence of $10 \%$ serum. For example, Oku et $\mathrm{al}^{31}$ also reported that in the presence of serum, PCL composed of PC and cetylated polyethylenimine had an enhanced gene transfer over PCL without serum. On the contrary, the efficiency of DOTAP liposomes or Lipofectamine was markedly suppressed in the presence of serum. To clarify the serum activation of PCL-mediated transfection, the authors examined the formation of DNA/ PCL complexes under a microscope. The PCL and DNA appeared as rather heterogeneous aggregates in the absence of serum but formed smaller and more homogeneous complexes in the presence of serum. Besides lipoplex size, many other parameters (eg, cationic lipids, cell type, and in vivo or in vitro environments) may also result in different transfection efficiencies.

\section{Cytotoxicity}

One of the major requirements of cationic vectors for gene delivery is low cytotoxicity. However, cationic polymers have been known to be cytotoxic materials. It is believed that the cytotoxic effect mainly originates from the inherent cationic charge, leading to polymer aggregation on cell surfaces, which impairs important membrane functions. The toxicity of cationic polymers is different depending on the polymer, the MW of the polymer, and the type of cells studied. Therefore, PEI, PLA, PCL, and their complexes with DNA at various weight ratios were investigated in this study for their cytotoxicities in HeLa and Huh7 cells. The half maximal inhibitory concentration $\left(\mathrm{IC}_{50}\right)$ values of PEI, PLA, and PCL in both cells are shown in Table 1. The higher
Table I Cytotoxicity (half maximal inhibitory concentration $\left[\mathrm{IC}_{50}\right]$ ) of polyethylenimine (PEI), poly-L-arginine (PLA), and PLAcoated liposomes in human hepatoma cell line (Huh7) and human cervical carcinoma (HeLa) cells

\begin{tabular}{lll}
\hline Samples & $I_{50}(\mu \mathrm{g} / \mathrm{mL})$ & \\
\cline { 2 - 3 } & Huh7 cells & HeLa cells \\
\hline PEI MW $25 \mathrm{kDa}$ & 54.1 & 1.7 \\
PLA MW $>70 \mathrm{kDa}$ & 70.0 & 5.5 \\
PLA MW $>70 \mathrm{kDa}$ & 70.3 & 10.6 \\
coated liposomes & & \\
\hline
\end{tabular}

Abbreviation: MW, molecular weight.

$\mathrm{IC}_{50}$ values indicated lower cytotoxicity for these complexes. Interestingly, the results revealed that the cytotoxicity in the HeLa cells was more than that in the Huh7 cells and that PLA had lower cytotoxicity than PEI in both cell lines. These activities might be the result of the biodegradability of PLA. In addition, the $\mathrm{IC}_{50}$ values of PCL were higher than those of PLA. Although the exact mechanism remains unclear, it is possible that the liposomes might increase the cell viability of PLA. This finding was similar to our previous study ${ }^{32}$ and also a study by $\mathrm{Hu}$ et $\mathrm{al},{ }^{33}$ who revealed that lipopolyplexes helped to decrease the cytotoxicity.

The cytotoxicity of PLA and PCL complexes with DNA at various weight ratios in the transfection experiments was performed in HeLa and Huh7 cells. Figure 5 shows the effects of the PLA/DNA and PCL/DNA complexes on cell viability. When the cells were incubated with $1 \mu \mathrm{g}$ of naked DNA, the cell viability remained almost the same as the control (nontransfected cells). Their average cell viability decreased when the carrier/DNA weight ratios increased. However, the viability was over $80 \%$ at the weight ratio of 2 (highest transfection). Therefore, this study clearly showed that PCL
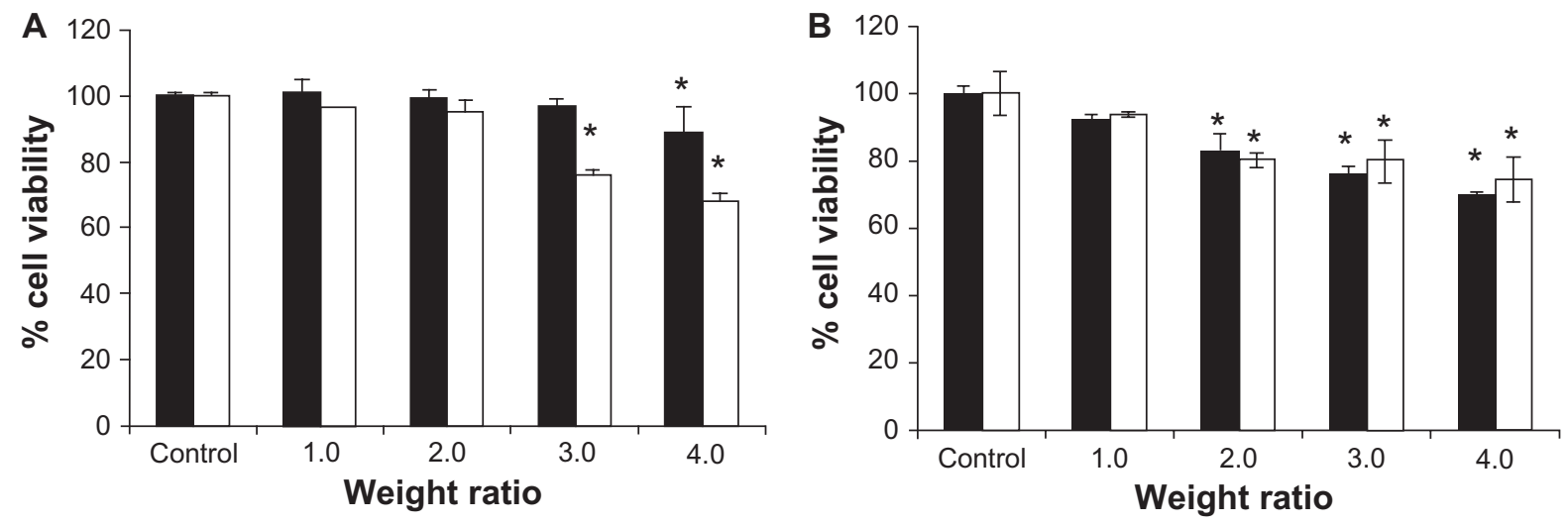

Figure 5 Comparison of the cell viability of ( $\mathbf{a}$ )poly-L-arginine (PLA)/DNA and ( $\square$ ) PLA-coated liposomes (PCL)/DNA complexes at various weight ratios in (A) human cervical carcinoma cells and (B) human hepatoma cell line cells.

Note: Each value represents the mean \pm SD of three wells. *Difference values were statistically significant $(P<0.05)$. 
is safe, which is similar to the finding from a previous study. ${ }^{32}$ Moreover, the PCLs were found to be an efficient gene delivery system that helped to increase cell viability.

\section{Conclusion}

PCLs were successfully used to improve transfection efficiencies of PLA. The ability of these novel PCLs to transfer functionally active DNA into the cell culture was found to be dependent upon the weight ratio and cell type. The transfection efficiency of the PLC was about two times higher than that of the PLA. This study suggested that PCLs are safe and significantly improve the gene delivery capability in vitro. These lipopolyplexes might also be useful for gene delivery.

\section{Acknowledgments}

The authors would like to acknowledge the financial support from the Research, Development and Engineering (RD\&E) Fund through the National Nanotechnology Center (NANOTEC), National Science and Technology Development Agency (NSTDA), Thailand (Project No. NN-B-22-EN3-17-52-10) to Silpakorn University, and the Silpakorn University Research and Development Institute (SURDI 54/01/11).

\section{Disclosure}

The authors report no conflicts of interest in this work.

\section{References}

1. Brown MD, Schatzlein AG, Uchegbu IF. Gene delivery with synthetic (non viral) carriers. Int J Pharm. 2001;229:1-21.

2. Ruponen M, Yla-Herttuala S, Urtti A. Interactions of polymeric and liposomal gene delivery systems with extracellular glycosaminoglycans: physicochemical and transfection studies. Biochim Biophys Acta. 1999;1415:331-341.

3. Karmali PP, Chaudhuri A. Cationic liposomes as non-viral carriers of gene medicines: resolved issues, open question and future promises. Med Res Rev. 2007;27:296-722.

4. Choi JS, Lee EJ, Jang HS, Park JS. New cationic liposomes for gene transfer into mammalian cells with high efficiency and low toxicity. Bioconjugate Chem. 2001;12:108-113.

5. Li P, Li D, Li G, Wang E. Cationic lipid bilayer coated gold nanoparticles-mediated transfer of mammalian cells. Biomaterials. 2008;29:3617-3624.

6. Lam AMI, Cullis PR. Calcium enhances the transfection potency of plasmid DNA-cationic liposome complexes. Biochim Biophys Acta. 2000;1463:279-290.

7. Ko YT, Kale A, Hartner WC, et al. Self-assembling micelle-like nanoparticles based on phospholipid-polyethyleneimine conjugates for systemic gene delivery. J Control Release. 2009;133: $132-138$.

8. Hanzlikova M, Soininen P, Lampela P, et al. The role of PEI structure and size in the PEI/liposome-mediated synergism of gene transfection. Plasmid. 2009;61:15-21.
9. Sugiyama M, Matsuura M, Takeuchi Y, et al. Possible mechanism of polycation liposome (PCL)-mediated gene transfer. Biochim Biophys Acta. 2004;1660:24-30.

10. Furuhata $M$, Izumisawa $T$, Kawakami $H$, et al. DecaargininePEG-liposome enhanced transfection efficiency and function of arginine length and PEG. Int J Pharm. 2009;371:40-46.

11. Tokunaga M, Hazemoto N, Yotsuyanagi T. Effect of oligopeptides on gene expression: comparison of DNA/peptide and DNA/peptide/ liposome complexes. Int J Pharm. 2004;269:71-80.

12. Rea JC, Gibly RF, Barron AE, Shea LD. Self-assembling peptidelipoplexes for substrate-mediated gene delivery. Acta Biometer. 2009; 5:903-912.

13. Kim HH, Lee WS, Yang JM, Shin S. Basis peptide system for efficient delivery of foreign genes. Biochim Biophys Acta. 2003;1640: 129-136.

14. Pedroso de Lima MC, Simones S, Pires P, et al. Cationic lipid-DNA complexes in gene delivery: from biophysics to biological applications. Adv Drug Deliv Rev. 2001;47:277-294.

15. Thomas M, Klibanov AM. Non-viral gene therapy: polycation-mediated DNA delivery. Appli Micro Biotech. 2003;62:27-34.

16. Pouton CW, Lucas P, Thomas BJ, et al. Polycation-DNA complexes for gene delivery: a comparison of the biopharmaceutical properties of cationic polypeptides and cationic lipids. J Control Release. 1998;53:289-299.

17. Ramsay E, Hadgaft J, Birchall J, Gumbleton M. Examination of the biophysical interaction between plasmid DNA and the polycations, polylysine and polyornithine, as a basis for their differential gene transfection in-vitro. Int J Pharm. 2000;210:97-107.

18. Choi HS, Kim HH, Yang JM, Shin YS. An insight into the gene delivery mechanism of the arginine peptide system: role of the peptide/DNA complex size. Biochim Biophys Acta. 2006;1760:1604-1612.

19. Goparaju GN, Satishchandran C, Gupta PK. The effect of the structure of small cationic peptides on the characteristics of peptide-DNA complexes. Int J Pharm. 2009;369:162-169.

20. Alves ID, Goasdoue N, Correia I, et al. Membrane interaction and perturbation mechanisms induced by two cationic cell penetrating peptides with distinct charge distribution. Biochim Biophys Acta. 2008;1780:948-959.

21. Futaki S. Membrane-permeable arginine-rich peptides and the translocation mechanisms. Adv Drug Deliv Rev. 2005;57: $547-558$.

22. Yang S, Coles DJ, Esposito A, et al. Cellular uptake of self-assembled cationic peptide-DNA complexes: multifunctional role of the enhancer chloroquine. J Control Release. 2009;135:159-165.

23. Furuhata M, Kawakami H, Toma K, et al. Design synthesis and gene delivery efficiency of novel oligo-arginine-linked PEG-lipid: effect of oligo-arginine length. Int J Pharm. 2006;316:109-116.

24. Choi JS, Nam K, Park J, et al. Enhanced transfection efficiency of PAMAM dendrimer by surface modification with L-arginine. J Control Release. 2004;99:445-456.

25. Opanasopit P, Tragulpakseerojn J, Apirakaramwong A, et al. Chitosan enhances transfection efficiency of cationic polypeptides/DNA complexes. Int J Pharm. 2011;410:161-168.

26. Mossman TJ. Rapid colorimetric assay for cellular growth and survival: application to proliferation and cytotoxicity assays. J Immunol Methods. 1983;65:55-63.

27. Chae Y, Jang MK, Nah JW. Influence of molecular weight on oral absorption of water soluble chitosans. J Control Release. 2005; 102:383-394.

28. Lee KY, Kwon IC, Jo WH, Jeong SY. Complex formation between plasmid DNA and self-aggregates of deoxycholic acid-modified chitosan. Polymer. 2005;46:8107-8112.

29. Son KK, Tkach D, Patel DH. Zeta potential of transfection complexes formed in serum-free medium can predict in vitro gene transfer efficiency of transfection reagent. Biochim Biophys Acta. 2000;1468:11-14. 
30. Yagi N, Yano Y, Hatanaka K, et al. Synthesis and evaluation of a novel lipid-peptide conjugate for functionalized liposome. Bioorg Med Chem Lett. 2007;17:2590-2593.

31. Oku N, Yamazaki Y, Matsuura M, et al. A novel non-viral gene transfer system, polycation liposomes. Adv Drug Deliv Rev. 2001;52: 209-218.
32. Opanasopit $\mathrm{P}$, Paecharoenchai $\mathrm{O}$, Rojanarata $\mathrm{T}$, et al. Type and composition of surfactants mediating gene transfection of polyethylenimine-coated liposomes. Int J Nanomedicine. 2011;6:975-983.

33. $\mathrm{Hu}$ Y, Li K, Wang L, et al. Pegylated immuno-lipopolyplexes: a novel non-viral gene delivery system for liver cancer therapy. $J$ Control Release. 2010;144:75-81.

\section{Publish your work in this journal}

The International Journal of Nanomedicine is an international, peerreviewed journal focusing on the application of nanotechnology in diagnostics, therapeutics, and drug delivery systems throughout the biomedical field. This journal is indexed on PubMed Central, MedLine, CAS, SciSearch $\AA$, Current Contents ${ }^{\circledR} /$ Clinical Medicine,
Journal Citation Reports/Science Edition, EMBase, Scopus and the Elsevier Bibliographic databases. The manuscript management system is completely online and includes a very quick and fair peer-review system, which is all easy to use. Visit http://www.dovepress.com/ testimonials.php to read real quotes from published authors. 